\title{
PROFESSIONAL DEVELOPMENT OF THE STATE OFFICE OF UKRAINE HUMAN RESOURCES
}

\author{
Kachan (Melnyk) Ya. V. \\ Ukraine, Kyiv, Ukrainian State Employment Service Training Institute \\ Associate Professor of Public Administration and Management department \\ DOI: https://doi.org/10.31435/rsglobal_wos/31072019/6607
}

\section{ARTICLE INFO}

Received: 27 May 2019

Accepted: 10 July 2019

Published: 31 July 2019

\section{KEYWORDS}

competence,

competence,

professional development,

public service,

employment service.

\begin{abstract}
The article deals with the clarification of the essence of professional development of public servants of the State Employment Service of Ukraine. The article proves that the requirements, which society nowadays places in the professional activity of public servants, envisage not only increased responsibility and effectiveness in its implementation, but also continuous improvement of the level of its professional qualification by civil servants. For public servants to qualify for their duties today it is not enough to possess only narrow-profile knowledge, they need the knowledge and understanding of the mechanisms of interaction of the state, society and individual citizens. It is established that for today professional development of public service is fundamental in the context of postgraduate education of civil servants, because any political strategies are formed and implemented through the human prism. The review of professional development is outlined as: systematically organized process of continuous professional training of the personnel for its preparation for implementation of new production functions, professional qualification promotion, formation of reserve managers and improvement of personnel structure; providing and organizing the learning process to achieve the goals set by the organization; improving skills and competences, expanding knowledge, raising competency, inclining and learning enthusiasm at all levels of the organization, contributing to continuous growth.
\end{abstract}

Citation: Kachan (Melnyk) Ya. V. (2019) Professional Development of the State Office of Ukraine Human Resources. International Academy Journal Web of Scholar. 7(37). doi: 10.31435/rsglobal_wos/31072019/6607

Copyright: (ㄷ 2019 Kachan (Melnyk) Ya. V. This is an open-access article distributed under the terms of the Creative Commons Attribution License (CC BY). The use, distribution or reproduction in other forums is permitted, provided the original author(s) or licensor are credited and that the original publication in this journal is cited, in accordance with accepted academic practice. No use, distribution or reproduction is permitted which does not comply with these terms.

Introduction. The effectiveness of any management structure and public including service bodies is largely determined by the selection of personnel, their professional training, business and human qualities, the ability to quickly and rationally perform their functional duties. It is not an exception for employees of the State Employment Service of Ukraine for whom the constant changes in the conditions associated with the ongoing reform of decentralization impose additional requirements. But today, not all of them meet these requirements. Obviously, the tasks of improving the organization of activities in public authorities, improving the quality and scale of training for work in these structures are of paramount importance, since their solution can dramatically increase the staffing potential and, as a consequence, the efficiency of public authorities.

Research results. In the current trend of development and improvement of the system of professional development of public employees of the State Employment Service of Ukraine should be directed to the maximum approximation of their acquired skills, knowledge, skills, as well as personal experience to the willingness to use them in professional activity. In this regard, civil service reform is recognized by the Strategy as one of its top priorities. The first steps have already been taken on this 
path: the Cabinet of Ministers of Ukraine has developed and approved the Strategy of reforming the state administration of Ukraine for 2016-2020; The Verkhovna Rada of Ukraine adopted the Law of Ukraine "On Civil Service". These regulations define the new tasks and principles of work of public servants, the implementation and adherence of which will bring the Civil Service Institute of Ukraine closer to European standards of management.

The demands that society places on the professional activity of public servants today imply not only an increase in responsibility and efficiency in its implementation, but also a constant improvement of the level of their own professional qualifications by civil servants. Today, public servants need to have only narrow-minded knowledge to perform their duties qualitatively, they need knowledge and understanding of the mechanisms of interaction between the state, society and individual citizens.

Today, in the process of gradual integration into the legal space of the European Union, Ukraine is persistently reforming the system of state-administrative relations. The European dimension of the reform is enshrined in the Law of Ukraine "On the Principles of Domestic and Foreign Policy" approved in 2010, it was identified as one of the main principles of the policy in the field of statebuilding, the modernization of the civil service, taking into account the European experience on the principles of professionalism and political neutrality [7].

The professional development of a public service involves the development of the personality of a public servant, which implies a certain dynamic of the properties and qualities expressed in the form of the "development" of the individual. However, the process of development is not just about growth and improvement. The influence of personality on professional development can be positive (choice of profession, quality of professional adaptation, development of professional creativity and skill) and negative, which impedes the formation of personality of professional (lack of positive motivation, presence of personal qualities, interfere with professional activity).

Today, the professional development of public service is fundamental in the context of postgraduate education for civil servants, since any political strategy is shaped and implemented through the lens of a person.

At this stage of social transformation, when human development and human beings, in particular, are at the center of the universe, the issue of professionalization of civil servants becomes not only relevant, but also determines the vector of development of countries and the planet as a whole. For Ukraine, professional training is particularly important not only in the light of global processes, but also in the context of the need for system-transforming reforms, which leads to the existence of a effective system of functioning of public administration entities. In turn, the training of civil servants involves unlocking the professional potential of a person, which is crucial for our country in the context of establishing an independent, strong European state.

Therefore, the main issues that Ukraine faces at the present stage of its operation raise the problem of professionalization of human resources, that is, people who are directly related to public service. Successful solution of this problem is possible if acmeologization of continuous professional education of civil servants.

According to A. Rachinsky and N. Zhidenko, formation of a democratic, legal, social state, development of civil society principles, integration of Ukraine into the standards of the European Union, carrying out administrative reform, including reform of the civil service, require the preparation of a new generation of heads and specialists of public authorities, formation of professionally trained personnel reserve for replacement of positions in the structures of the state apparatus [9, p. 10].

So, in order to find out the essence of professional development of public employees of the State Employment Service of Ukraine, let us turn to the basic definitions of professional development.

According to the scientist $\mathrm{O}$. Zhyglo, professional development is a balanced, non-equilibrium and open process of personality change as a result of mastering and performing vocational, educational and professional activities [3].

Quite often, professional development in contemporary literature is regarded as the main learning outcome, which is defined as:

- system-organized process of continuous professional training of staff to prepare him for the performance of new production functions, professional qualification promotion, formation of a reserve of managers and improvement of staff structure;

- providing and organizing a training process to achieve the goals set by the organization; 
- improving skills and competences, expanding knowledge, enhancing competence, aptitude for training and enthusiasm of employees at all levels of the organization, which contributes to continuous growth [2, p. 259].

Therefore, professional development of personnel is a rather complex system and continuous process, which is implemented through a complex of educational, practical, socio-cultural, communication and motivational measures aimed at training, professional development, development of business qualities, social and personal development, assessment and adaptation. personnel to production and organizational changes [1, p. 132].

To approach the professional development of public servants from an academic point of view, it is necessary to speak about continuous improvement of qualification, acquisition of new knowledge and improvement of already existing ones. It is necessary to talk about improving the skills, skills and practices of communication with people. And the important factor that determines professional development should be the functional requirements of the position, opportunities for the development of each individual, already acquired knowledge and skills. Must also take into account existing experience in management positions, which could potentially be useful in work. It is impossible to achieve the required level of professionalism unless the employee develops and grows professionally.

The new Law of Ukraine "On Civil Service" approves the use of a competent approach in the system of training civil servants. It should be noted that a competent approach was a reaction of the training system to changing socio-economic conditions and processes caused by the development of a market economy. This modern approach, implemented in the countries of the European Union, not only changes the content of vocational training, but in an organic combination with modern technologies of organization of vocational training, retraining and advanced training of personnel, has become an effective tool for personnel management and organization of its training on the basis of the system of professional competences. According to A. Kazanovsky, this is a manifestation in the organic combination of functional and personal characteristics of employees, which are necessary for the successful performance of professional activity and is a manifestation of competencies as the basis for the formation of professionalism [4].

For a public servant, his or her professional competence can be considered as conformity and consistency between the requirements for the position (qualification characteristics) and the level of professionalism, personal qualities that he is ready to show for the most effective work in a position (socialprofessional performance). Continuous and continuous professional development, professional development should become the main focus of personnel policy when it comes to improving the professional competence of employees. The initial formation of professional competence, its formation and its further development should be continuous and should accompany all stages of service in public positions.

Domestic Researchers M. Sudakov, L. Fokas, competence is understood as professional knowledge of the basics and technologies of professional activity, as well as effective methods and means of achieving the goals, a set of acquired professional knowledge, the ability to implement them to perform professional functions and tasks [8, p. 7].

We emphasize that the formation and development of professional competence of staff involves certain institutional channels, procedures for staff evaluation (assessment, certification, examinations, etc.), its external professional motivation (stimulation) within the control function, as well as other factors professional orientation, adaptation, activation, training, education. Determining the level of competence of a civil servant, according to $\mathrm{M}$. Nynyuk, includes checking his observance of the general rules of conduct, patriotism, assessment of personal moral virtues (fairness, diligence, responsibility, honesty, kindness, tolerance, tact, etc.); the incentive of professional activity in the civil service is the personal example of a manager [6, p. 561]. The professionally important qualities of a civil servant, mentioned by M. Ninyuk, relate primarily to his professional culture, which, on the one hand, shapes the professionalism of the personnel, and on the other - may not be the only criterion for assessing professional competence.

In the scientific literature, along with the discussion of what constitutes professional competence, the process of defining the most important professional qualities of a civil servant, the "ideal of his activity", continues. The importance of a detailed study of the status of a civil servant and the scope of his / her competence is emphasized in order to clearly define his / her professional competence. It is rightly emphasized that in its present form it (ideal, model of professional activity) is unlikely to exist as such. It is probably stated that the professionally important qualities of a civil servant, developed by science, can hardly be called as such that can be used in practice. This is due to 
the fact that the profession and professional activity of the civil servant are complex, and therefore any attempt to complete their descriptions is doomed to failure.

In the EU Member States, a method was sought to meet the basic requirements for a position or type of position, and a decent assessment of the merits of civil servants in the course of their career development is a key condition for professionalization of the service [10, p. 66]. This approach is logical, for example, for yesterday's graduates of higher education, in which professional skills, experience and experience can be shaped over time. Most often, professional competence is considered the basis of professionalism. However, from our point of view, at least professional culture, professional training and professional experience should be included in this framework. Formation of these qualities of staff is in interaction with each other. For example, it is not possible to form a high and stable level of professional culture without professional experience, and vice versa. The logic of substantiating such a view on the content of professional competence is indicated by the opinion of $\mathrm{N}$. Lypovska, who calls professional competence the main cognitive component of the subsystem of professionalism of activity [5].

The divergence of concepts, the absence of clear and generally accepted definitions often lead to the notion that the terms "professional development" and "vocational training" are considered identical and equivalent. In most cases, there is a substitution of one concept for another. If we approach these definitions more broadly, "vocational training" is only part of "professional development". Vocational training is the process of acquiring the knowledge necessary to eliminate the mismatch between the required amount of knowledge and skills and that of the employee at the current time. Professional development is a broader concept and includes not only the process of acquiring knowledge, but also exploring the possibilities of their application, the growth of personal, not just professional. It is imperative that professional development should include the development and improvement of the qualities necessary for the individual to be able to exercise his or her authority. Vocational training is significant, but only part of professional development.

The result of resolving all these issues should be the realization of the right of a public servant to receive a vocational education, including additional education.

\section{REFERENCES}

1. Borisova E.A Personnel management for modern executives / EA Borisova. - St. Petersburg.: Peter, 2003. - 445p.

2. Grinova V.M. Administrative management of labor potential: textbook. tool. / V.M Grinyova, M.M. Novikov, M.M. Salun, O.M Krasnonosov; edition of Doctor of Economics. of sciences, prof. V.M. Grinyova. - Kh.: Edition of KhNEU, 2004. - 428 p

3. Zhyglo O.O. Development of Teacher Information Culture [Electronic resource] - Access mode: http://eprints.kname.edu.ua/31237/1/25.pdf

4. Kazanovsky A.V. Development of the profile of competencies of managerial staff of the basic employment center: the facets of the problem / AV Kazanovsky // Labor Market and Employment, 2012. - №2. - P.19-23

5. Lypovskaya, N.A. Interpretation of professional competence of specialists in acmeological discourse / NA Lipovskaya // Theoretical and applied issues of state formation. - 2009. -issue. 5 [Electronic resource] National Library of Ukraine. V.I. Vernadsky. - URL: http://www.nbuv.gov.ua/ujm/e-joumals/tppd/2009-1/zmist/R 3 / Lipovska.pdf

6. Nynyuk, M. Peculiarities of Formation of Moral and Ethical Qualities of Civil Servants in the Conditions of Ukraine's Integration into the World Community [Text] / M. Ninyuk // Effectiveness of Public Administration in the Context of Globalization and European Integration: Materials of Scientific Pract. Conf. for the international part. (May 29, 2003, Kyiv): [in 2 volumes]. - K.: NADU, 2003. - Vol. 2. - P. 560-562.

7. On the Principles of Domestic and Foreign Policy [Electronic resource]: Law of Ukraine of July 12010 No. 2411-VI. - Access mode: http: // zakon4.rada.gov.ua/laws/show/2411-17

8. Professional competence of the head of the basic employment center: [monograph] / MV Sudakov, A.V. Kazanovsky, L.M. Fokas and others; [edit] Sudakov]. - K.: PIC DSGU, 2GD - 167 p.

9. Rachinskiy A.P.Providing Professional Development of Civil Servants: The Experience of the Republic of Lithuania / AP Rachinsky, NA Zhidenko // Bulletin of the National Academy of Public Administration under the President of Ukraine. - 2014. - № 1. - P. 10-18.

10. Development of efficiency and professionalism in the civil service (SIGMA publ.) [Text] / trans. S.M. Ozirska. - K.: UADU, 2000. - 82 p. 